\title{
Phylogenetic diversity of larval Chironomidae (Diptera) in lowland rivers as a potential tool in assessment of environmental quality
}

\author{
Paweł Koperski 1
}

Received: 18 October 2018/Revised: 6 March 2019/Accepted: 22 March 2019/Published online: 30 March 2019

(C) The Author(s) 2019

\begin{abstract}
Different components of biological diversity of larval Chironomidae, typically the most abundant and the most diverse of all lotic zoo-benthos, were assessed to determine their suitability in prediction of the environmental quality. Animals were collected as 73 samples at 62 riverine sites on the territory of Poland and identified morphologically. The analysis of nonlinear regression was used to compare the suitability of the seven indices of diversity. Traditional indices of taxonomic diversity (taxonomic richness, Margalef and Shannon indices) and indices of taxonomic distinctness were found to be unsuitable for this purpose because of the unimodal type of response of their values along with the gradient of the environmental quality. Contrary to them, values of two measures of phylogenetic diversity monotonically increased along with the values of environmental quality measured by official index MMI (Multimetric Macroinvertebrate Index) and were
\end{abstract}

Handling editor: Marcelo S. Moretti

Electronic supplementary material The online version of this article (https://doi.org/10.1007/s10750-019-3942-7) contains supplementary material, which is available to authorized users.

P. Koperski $(\bowtie)$

Department of Hydrobiology, Faculty of Biology,

Biological and Chemical Research Center, University of

Warsaw, Żwirki i Wigury 101, 02-089 Warsaw, Poland

e-mail: p.t.koperski@uw.edu.pl considered highly useful. The best fitted functions estimating relationships between MMI and both indices of phylogenetic diversity (total phylogenetic distance and quadratic entropy) were statistically highly significant and have high values of the fitaccuracy parameters. Original index of phylogenetic diversity ChiPDi based on total phylogenetic diversity, quadratic entropy and taxonomic richness has been presented as well as the proposal of related procedure using barcoding methods.

Keywords Benthos - Biological assessment . Diversity $\cdot$ Macroinvertebrates $\cdot$ Nonlinear . Phylogenetic distance

\section{Introduction}

Water Framework Directive (Directive, 2000/60/EC of the European Parliament and of the Council-2000) introduced the term environmental quality of aquatic ecosystems, defined as a quality of their structure and functioning (Furse et al., 2006) for general use in the literature on environmental assessment. One of the most important parameters characterizing structure and functioning of lotic environments and describing their ecological status are taxonomic richness and diversity of aquatic organisms. As a consequence, different diversity indices were developed and 
acquired a central importance in environmental monitoring and conservation, allowing the comparison among aquatic communities in different types of environments, attending to different taxa and trophic levels. Magurran (2013) presented the long history of the use of diversity indices in freshwater monitoring with reference to different methods, particularly those related to diversity of benthic invertebrates that have been expressed in different ways (Bailey et al., 2004). However, there is no general agreement about which indices are more appropriate and informative, and the multitude of developed indices makes biological diversity difficult to quantify for purposes of biological assessment (Yoccoz et al., 2001). Additionally, the application of traditional taxonomic diversity indices (e.g., Shannon, Margalef, Simpson) in freshwater biological assessment frequently seems inadequate (Lydy et al., 2000). In some cases, traditional indices of taxonomic diversity are not suitable for the purposes of biological assessment because of unimodal (hump-like) distribution of their values along with the gradient of ecological disturbance (Bini et al., 2014; Koperski, 2017). This type of response makes it difficult to distinguish the values of diversity indices at high values of ecological quality from those at low values (De Pauw \& Vanhooren, 1983; Barbour et al., 1999) Commonly, assessment of benthic invertebrate diversity contains mixed-level taxonomic identification or species-level identification of selected taxa with high indicative value (Bailey et al., 2001). Treating species or other taxa as being equal (Schweiger et al., 2008) in spite of their various genetic distances seem to be an important weakness of traditional measures of taxonomic diversity. Measures of phylogenetic diversity based on mutual phylogenetic relationships among species have been developed to solve this problem. Different measures of the distance between species or other taxa can be used to estimate this type of diversity: taxonomic distinctness (Warwick \& Clarke, 1995; Clarke \& Warwick, 1998), elapsed time of taxa divergence and genetic distance (Faith et al., 2009). Measuring diversity in terms of accumulated evolutionary history provides certain additional value to applied ecology (Schweiger et al., 2008). The suitability of molecular-based phylogenetic studies using barcoding methods for conservation ecology was demonstrated by Faith \& Baker (2006) and Winter et al. (2013) and for biological monitoring by Carew et al. (2011).
Chironomid larvae are typically the most abundant of all freshwater benthic macroinvertebrates. Some species are ubiquitous and have been found to display a wide range of tolerance, while the others occupy the extremes of numerous ecological variables (Pinder, 1995). The range of variability in feeding behavior and lifestyles observed within family Chironomidae seems to be wider than in any other family of aquatic insects (Franquet, 1999) despite specialized requirements exhibited by the larvae of certain chironomid species. It can provide a great deal of information about the effects of pollution (Lindegaard, 1995) and other anthropogenic disturbances in freshwater systems, especially when detailed taxonomic identification is attained (Cranston, 1995). In numerous studies, however, Chironomidae larvae, treated as a family, are not a good indicators of environmental pollution because the differences in abundance of individuals between clean and polluted rivers are not significant (Kownacki, 2000). The identification of Chironomidae to the level of family or subfamily masks genus and species sensitivities (Serra et al., 2017) and a reduction of the taxonomical precision from species to genus level can lower the statistical significance of assessed environmental preferences (Orendt, 2018). Moreover, the effects of natural factors as: hydraulic characteristics (Syrovatka et al., 2009), discharge intensity (Grzybkowska et al., 1996), seasonality (e.g., Grzybkowska et al., 2003), and habitat heterogeneity (Franquet, 1999; Rae, 2004) may make the effects of environmental degradation on the structure of chironomid assemblages unclear. Environmental quality seems to be one of the important factor influencing diversity of lotic chironomid assemblages (Orendt, 2018). It was found in numerous studies that taxonomic composition of lotic chironomids might be determined directly by chemical pollution (Lindegaard, 1995, De Bisthoven \& Gerhardt, 2003), nutrient enrichment (e.g., Rae, 1989; Moore \& Palmer, 2005), suspended organic matter enrichment (Grzybkowska et al., 1996) and change along with the type of land use in the drainage area (Moore \& Palmer, 2005). Decrease in taxonomic diversity of Chironomidae along with increasing degradation of streams and rivers has been demonstrated (De Bisthoven \& Gerhardt, 2003; Koperski, 2009) but Serra et al. (2017) presented results showing the lack of significant changes in richness due to degradation. However, all of these studies concerned only selected degrading 
factors constituting environmental quality and covered only part of its variability-therefore, it is still difficult to reach final conclusions. A modern, analytically advanced method of using data on the composition of Chironomidae in lotic environments for the purposes of biological assessment in the form of an original index presented Milošević et al. (2018).

Chironomidae is a rich insect family, with 440 species found in Poland (Siciński, 2007), more than 1200 in Europe (Spies \& Saether, 2004), with worldwide estimates of 4147 aquatic species that are most certainly underestimated (Ferrington, 2008). Because Chironomidae larvae are difficult to identify when compared with other riverine insects, some authors (e.g., Rabeni \& Wang, 2001) suggested removing them from the protocols to make bioassessment methods more efficient, ignoring their great potential in biological monitoring.

Genetic-based approaches are a powerful alternative in case of groups with potential as biological indicators at high taxonomic resolution levels and difficult to identify otherwise. Many studies have already been conducted on genetic similarity or genetic distance within the Chironomidae to establish phylogenetic relationships between taxa (Ekrem et al., 2007), or to allow proper taxonomic determination (Sari et al., 2012). Different regions of nuclear and mitochondrial DNA were analyzed using a variety of methods to reveal phylogenetic relationships within this group. The great potential of barcoding methods of phylogenetic analysis of chironomid assemblages for the purposes of biological assessment was reported by Pfenninger et al. (2007) and Carew et al. (2003, 2013).

The main aim of this study was to determine which component of this family's diversity (taxonomic diversity, distinctness and phylogenetic diversity) is a better predictor of environmental quality in lowland rivers. To pursue this aim, the strength of the relationships between seven diversity indices and environmental quality, expressed as coefficients of nonlinear regression and measures of regression fit accuracy to achieve, was used. It was assumed that the strength of correlation and fit accuracy of regression models are the most important, decisive criteria to assess value of an index as a predictor of environmental quality. Well-known diversity indices, currently used as metrics in biological assessments of environmental quality, were compared with phylogenetic indices in terms of their explaining value being a measure of their potential suitability. Indices based on phylogenetic relationships are expected to correlate better with environmental quality than indices based on taxonomy and taxonomic distinctness as in the case of Hirudinea (Koperski, 2017). If that is the case, phylogenetic distance (PD) indices could be considered as a better tool to discriminate sites classified in different environmental quality classes. As a tool of this kind of discrimination, an original index based on indices of phylogenetic diversity will be proposed.

\section{Methods}

Sampling sites

Larvae of the family Chironomidae were collected with 73 samples of bottom invertebrates at 62 sites differed in environmental quality and located on 13 lowland rivers on the territory of Poland (Fig. 1). The samples were collected once (62 sites) or twice (11 sites) at each site between May 2011 and July 2012 by Regional Inspectorates of Environmental Protection (RIEP) and by the scientific team cooperating with the National Foundation of Environmental Protection, Warsaw, Poland. Applied sampling procedure is recommended, after minor modifications, under the name RIVECO, to assess the ecological status of flowing waters in accordance with requirements of the WFD (Bis \& Mikulec, 2013). Each sampling site was classified into one watercourse type considering the combination between: 26 abiotic and six biocoenotic types of watercourses, established in Poland on the basis of RIEPs' databases. Sites presented below were finally divided into three groups (Table 1), and all analyses were performed separately for each group. The sampling sites were selected by RIEP's staff assuming their representativeness for a given type of watercourses. The ecological status of each sampling site in 2011 or 2012 was taken from archival databases available on the websites of Voivodship Inspectorates of Environmental Protection (available at web portal http://www.gios.gov.pl/). The classification is based on the results of environmental quality assessment expressed by the values of MMI (Multimetric Macroinvertebrate Index) being an official multimetric biotic index dedicated to biological assessment of 
Fig. 1 Map of Poland with river network marked and sampling sites classified into three groups differed in terms of abiotic and biocoenotic characteristics; black circles_-sites of type 5-1, white circles-sites of type 5-2, triangles - sites of type 6

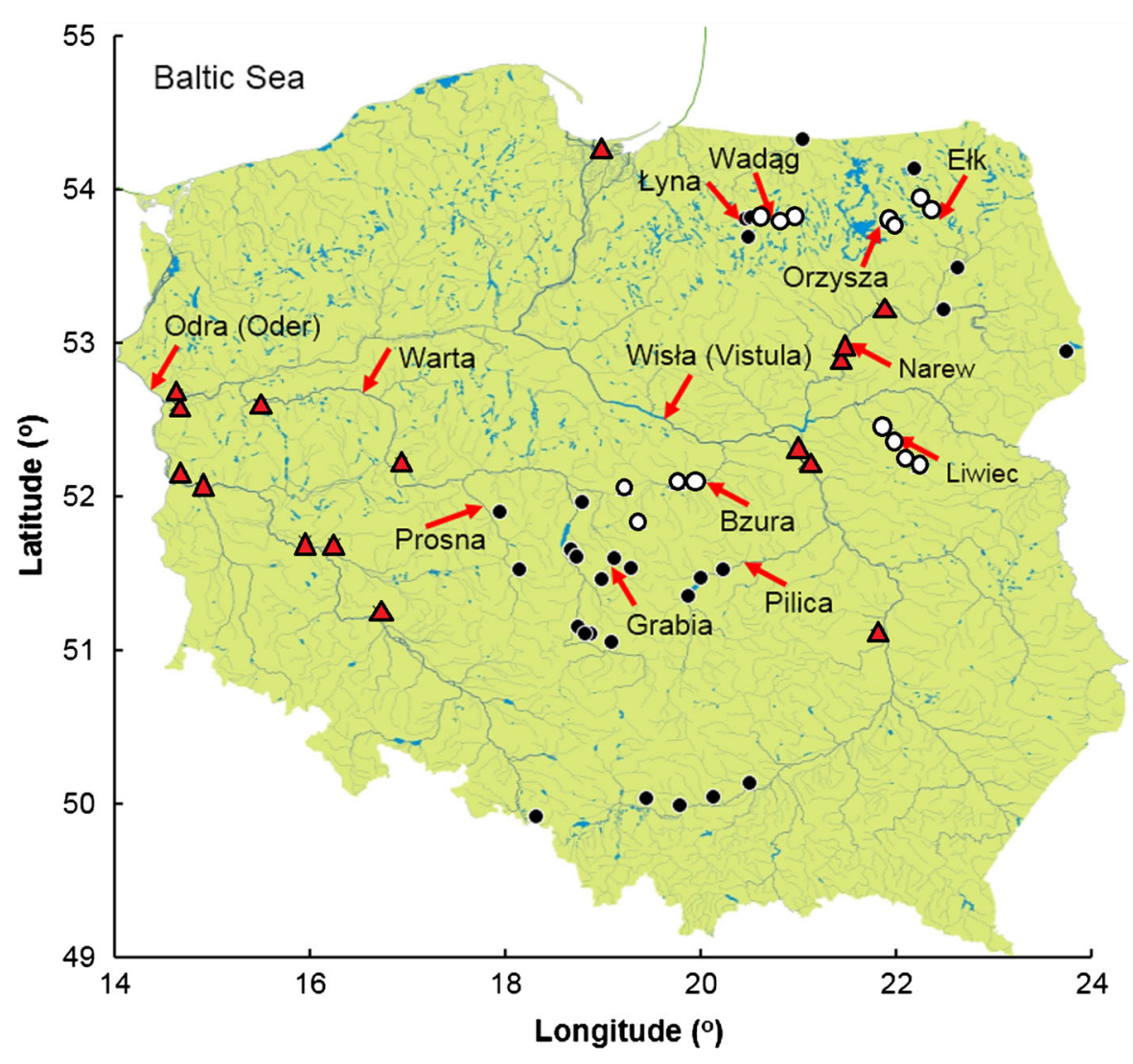

Table 1 Classification of sampling sites in terms of biocoenotic and abiotic typology (Bis \& Mikulec, 2013)

\begin{tabular}{|c|c|c|c|}
\hline $\begin{array}{l}\text { Group of } \\
\text { sites }\end{array}$ & Biocoenotic types & Abiotic types & $\begin{array}{l}\text { Number of } \\
\text { sites }\end{array}$ \\
\hline \multirow[t]{2}{*}{$5-1$} & \multirow[t]{2}{*}{$\mathrm{V}$-lowland and estuarine rivers } & $\begin{array}{l}\text { 19-rivers with sandy-clay substrate and catchment } \\
\text { area } 10^{2}-10^{5} \mathrm{~km}^{2}\end{array}$ & 32 \\
\hline & & $\begin{array}{l}20 \text { - rivers with gravel substrate and catchment area } \\
10^{2}-10^{5} \mathrm{~km}^{2}\end{array}$ & 4 \\
\hline $5-2$ & $\mathrm{~V}$-lowland and estuarine rivers & $\begin{array}{l}21-\text { great lowland rivers with catchment area larger } \\
\text { than } 10^{5} \mathrm{~km}^{2}\end{array}$ & 17 \\
\hline \multirow[t]{2}{*}{6} & \multirow{2}{*}{$\begin{array}{l}\text { VI-rivers with organic substrate and rivers } \\
\text { connecting lakes }\end{array}$} & 24 -rivers flowing through peatland valleys & 11 \\
\hline & & 25 -rivers connecting lakes & 9 \\
\hline
\end{tabular}

watercourses in Poland (Bis \& Mikulec, 2013). The value of MMI is a weighted average of six, mathematically transformed core metrics, widely used in biomonitoring and based on composition of macrozoobenthos: 1. ASPT (Average Score Per Taxon, based on BMWP index), 2. EPTD (sum of individuals from selected families of Ephemeroptera, Plecoptera, Trichoptera and Diptera), 3. GOLD (percentage of
Gastropoda, Oligochaeta and Diptera in a sample), 4. total family richness, 5. EPT (richness of Ephemeroptera, Plecoptera and Trichoptera families in a sample) and 6. Shannon diversity index. The values of these indicators correlate with the intensity of particular types of environmental degradation: organic pollution, hydromorphological disturbance, toxicity and general environmental degradation (Bis \& 
Mikulec, 2013; Galas et al., 2014) in accordance with assumptions presented by Buffagni et al. (2005).

\section{Identification}

Chironomidae larvae were sorted from the samples; a total of 100 individuals per sample were randomly chosen (the whole sample with the preserving solution was placed in a $400 \mathrm{ml}$ cuvette with gridded bottom, thoroughly mixed and then specimens were individually randomly selected until reaching 100) and then identified under microscope to the highest level of taxonomic resolution, following taxonomic keys: Cranston (1982), Cranston et al. (1983), Fittkau \& Roback (1983), Klink \& Moller-Pillot (2003), Oliver (1983), Pinder \& Reiss (1983), Saether (1983), Vallenduuk \& Morozova (2005) and Larocque-Tobler (2014), with the help of keys available at http:// chirokey.skullisland.com (Cranston, 2010). All final levels of identification are presented below as "species/morphospecies", while the richness of these forms is presented below as "taxonomic richness".

Two types of rarefaction procedures were used to make more convincing the comparisons of the species richness between samples. Individual Rarefaction with Kreb's method and estimation with log Gamma function was used to check the influence of the number of individuals in the sample on the estimated species richness. Species accumulation curves using presence/ absence data (Sample Rarefaction with Mao-tau function and Michelis-Menten function for extrapolation) were used to estimate the impact of increasing the number of samples from sites classified in terms of ecological quality and abiotic typology of the watercourses for estimated species richness. In this method, samples from sites belonging to the same type and the same ecological status are treated as subsequent samples from the same environment. PAST 3.17 software (Hammer et al., 2001) was used to carry out both procedures.

\section{Diversity}

Values of seven indices of diversity were calculated for each sample: taxonomic richness (TaxaS), two traditional, well-known indices of diversity (Shannon index and Margalef index), two indices of distinctness: taxonomic diversity (Taxadiv) and taxonomic distinctness (Taxadis) (Warwick \& Clark, 1995) and two indices of phylogenetic diversity: total phylogenetic distance (TPD, based on presence/absence data) and quadratic entropy (QE, based on relative abundances). To calculate taxonomic diversity and taxonomic distinctness six levels within family Chironomidae were taken into account: subfamily, tribe, genus, subgenus, group of species, species-it means that the distance between two species belonging to different subfamilies equals 5 .

Indices of phylogenetic diversity were calculated on the basis of the values of phylogenetic distance estimated for each pair of species found in a sample (TPD) and for each pair of individuals in a sample (QE). The estimation of phylogenetic distance between species/morphospecies consisted of two steps: 1. the estimation of the distance among genera and 2. the estimation of the distances between branches representing species/morphospecies and the node representing genus.

In step 1 data on distance between most of the genera were obtained from Cranston et al. (2012), which were supplemented by standardized data presented in other studies presenting results based on COI sequences and analyzed with Bayesian methods (Krosch et al., 2017; Montagna et al., 2016; and Demin et al., 2011). The lack of certain data in the analysis by Cranston et al. (2012) caused by the absence of several genera (Beckidia, Robackia, Demicryptochironomus) was completed by with using average distances from genera of the former "Harnischia complex" (Sæther, 1977) (Harnischia, Parachironomus, Paracladopelma, Cryptochirono$m u s)$. Distance data from sources other than Cranston et al., 2012 were expressed in relation to the respective distances from Cranston's study.

In step 2 distances among particular species/morphospecies and respective generic nodes were estimated as standardized, average branch length leading to generic nodes within the group or species (tribe, genus, subgenus) for which such data were found (e.g., Guryev et al. (2001) in case of Chironomus, Sinclair \& Gresens (2008) in case of Cricotopus, Sari et al. (2012) in case of different Orthocladiinae, Ekrem \& Willassen (2004) in case of Tanytarsini). It means that reciprocal distances between all species/morphospecies belonging to the same genus were equal.

For each pair of species/morphospecies, the distances determined in the first and second step have been summed up. Before addition they were 
standardized because both types of estimation could be carried out by different methods-the range of distance between particular species and respective generic nodes have been aligned with the range of species-genus distance found in data of Cranston et al. (2012). Summarized, final values of distance between pairs of species/morphospecies were transformed to scale $0-1$ in relation to the longest distance and then put to the matrix of phylogenetic distances between all species/morphospecies and then the resulting distance was recognized as the relative distance between species. PAST 3.17 software (Hammer et al., 2001) was used to calculate values of Taxadiv and Taxadis; FunctDiv software (Lepš et al., 2006) was used to calculate values of QE, finally for the computation of TPD Visual Basic (Excel 2013, Microsoft Office) was carried out.

\section{Statistical analysis}

The significance of statistical differences in abundance of dominant species between groups of sites was tested with Mann-Whitney test with Bonferroni correction (PAST software; Hammer et al., 2001).

\section{Regression analysis}

The values of indices presented were estimated as a parameters directly related to the environmental quality data (MMI) with using the analysis of nonlinear regression. Best fitted type of relation was established, and equations for each function were calculated. To test and to compare the fit accuracy of each regression $R^{2}$ coefficient, value of $F$ function with their $P$ value and residual coefficient of variance (RCV) were calculated in accordance with robust procedure. Regression analysis was processed with using Statistica.12 and PAST 3.17 software (Hammer et al., 2001) packages.

\section{Results}

The results were based on morphological taxonomic identification of 7300 individual larvae of Chironomidae. A total of 81 taxa were identified, including 51 species, 24 species groups, 2 subgenera, 4 genera. Additionally distinct morphotypes were recognized: 2 within a genus, 4 within a subgenus, and 8 within a group of species.

There were not any distinct, significant differences among the abundances of common species (occurred in frequency higher than $20 \%$ of sites of at least two groups of watercourses) between groups of sites classified neither in terms of biocoenotic typology nor in terms of environmental quality status (Supplementary Material). Frequency of rare species (occurred with a frequency lower than 10\%) did not differ statistically neither among groups of sites classified to different quality classes (Fig. 2a) nor among abiotic/ biocoenotic groups of sites (Fig. 2b).

Results of Individual Rarefaction are presented as curves based on averaged values for groups of samples from the sites belonging to the same type and the same ecological status with estimated SD (as unconditional variance; Colwell et al., 2012) (Fig. 3). In this method,
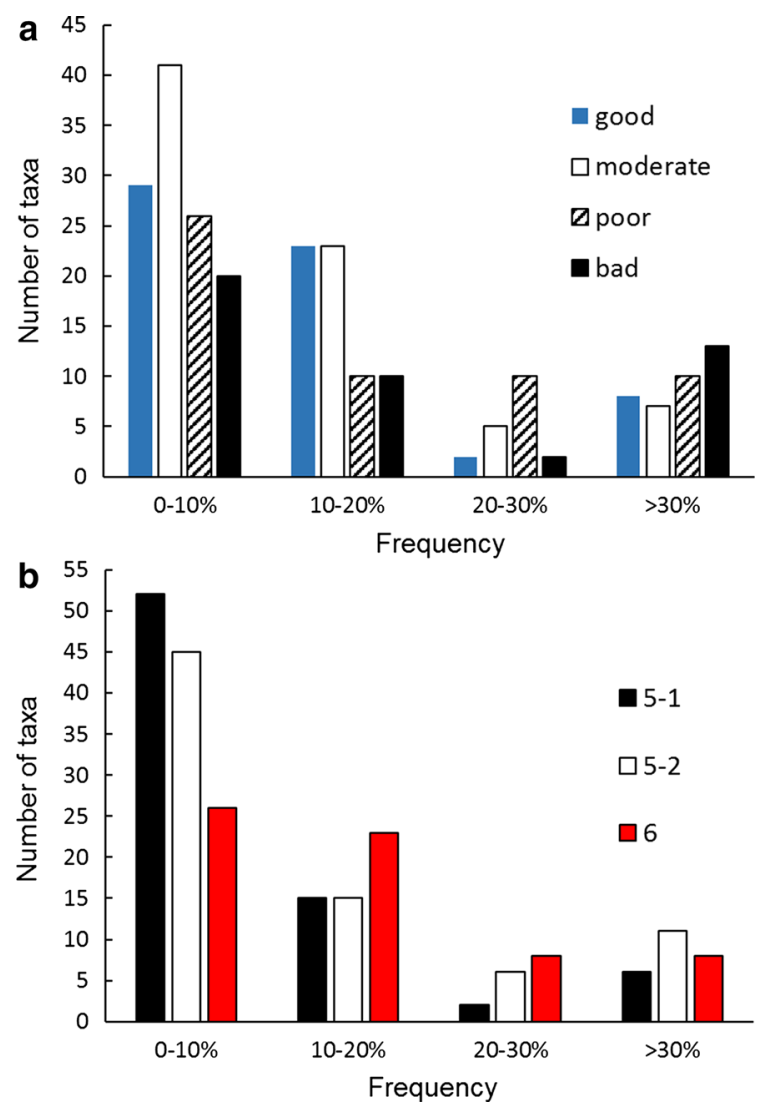

Fig. 2 Number of taxa (species and morphospecies) occurred with a given frequencies at a sites: a classified to different environmental quality classes; $\mathbf{b}$ classified to the groups differed in terms of abiotic and biocoenotic typology 

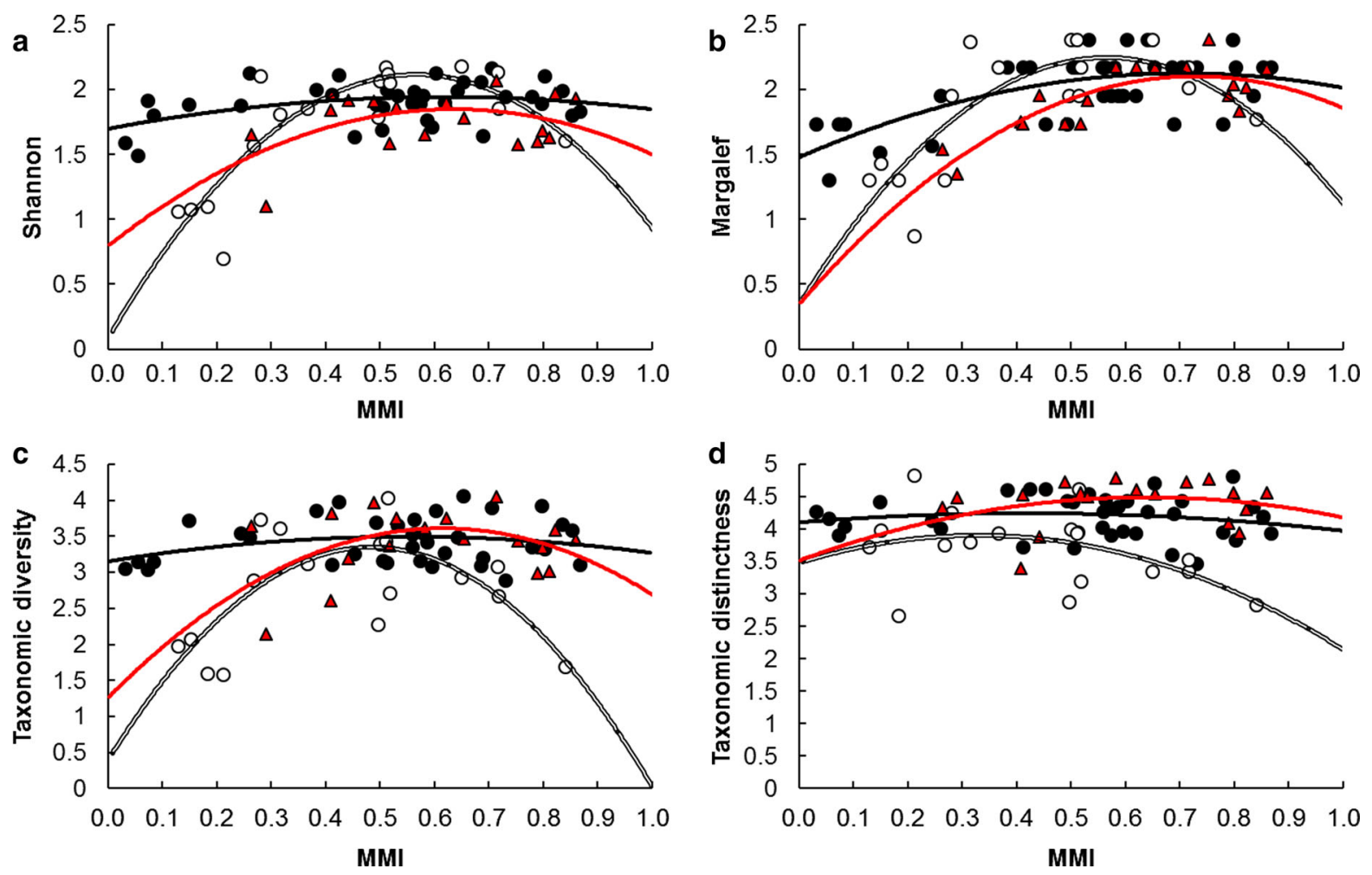

Fig. 3 The results of Individual Rarefaction presented as curves based on averaged values for groups of samples from the sites belonging the same ecological status with estimated

mathematical extrapolation of estimated species richness for larger numbers is not recommended. It can be easily deduced from the slope of the curves that increasing the number of identified animals up to 200 individuals will bring no more than approximately $15 \%$ increase in species richness. Results of Sample Rarefaction are presented as the curves of species accumulation with trend extrapolation, prepared for the groups of samples from sites belonging to the same type and the same ecological status (Fig. 4). As the number of samples increases up to 20 the estimated richness increases by about $25 \%$. The slope of the curves and accumulation rate of species for samples with intermediate MMI values of the type 5-1 and 6 is the highest. In group of samples belonging to type 5-2 values of those parameters are independent of ecological status.

Best fitted nonlinear regression functions were constructed independently for each of three types of watercourses and for seven parameters of diversity. Strength of relationships, measured by $R^{2}$ which was

SD. a type 5-1, b type 5-2, c type 6; - - - Equation 2, EQ 3,-ーーEQ 4,

highest at the sites classified as Group 5-2, except Margalef index, which were observed as the highest at sites of Group 6. Both traditional indices of species diversity and both indices of taxonomic distinctness show unimodal (binomial) relationships with environmental quality in all types of the rivers (Fig. 5). Generally, their maximal values were observed at values of MMI ranged between 0.5 and 0.7 . Fit accuracy measured by $F$-function was nonsignificant in most of these cases (Table 2), but binomial functions were the best fitted of all tested regression functions. Contrary to them values of species richness and two measures of phylogenetic diversity monotonically increased along with the values of environmental quality (Fig. 6). The best fitted logarithmic function estimating relationships between MMI and those indices were statistically highly significant and have relatively high $R^{2}$ (Table 2).

Finally, new combined index ChiPDI (Chironomid Phylogenetic Diversity Index), based on the values of the taxonomic richness (TaxaS), quadratic entropy 

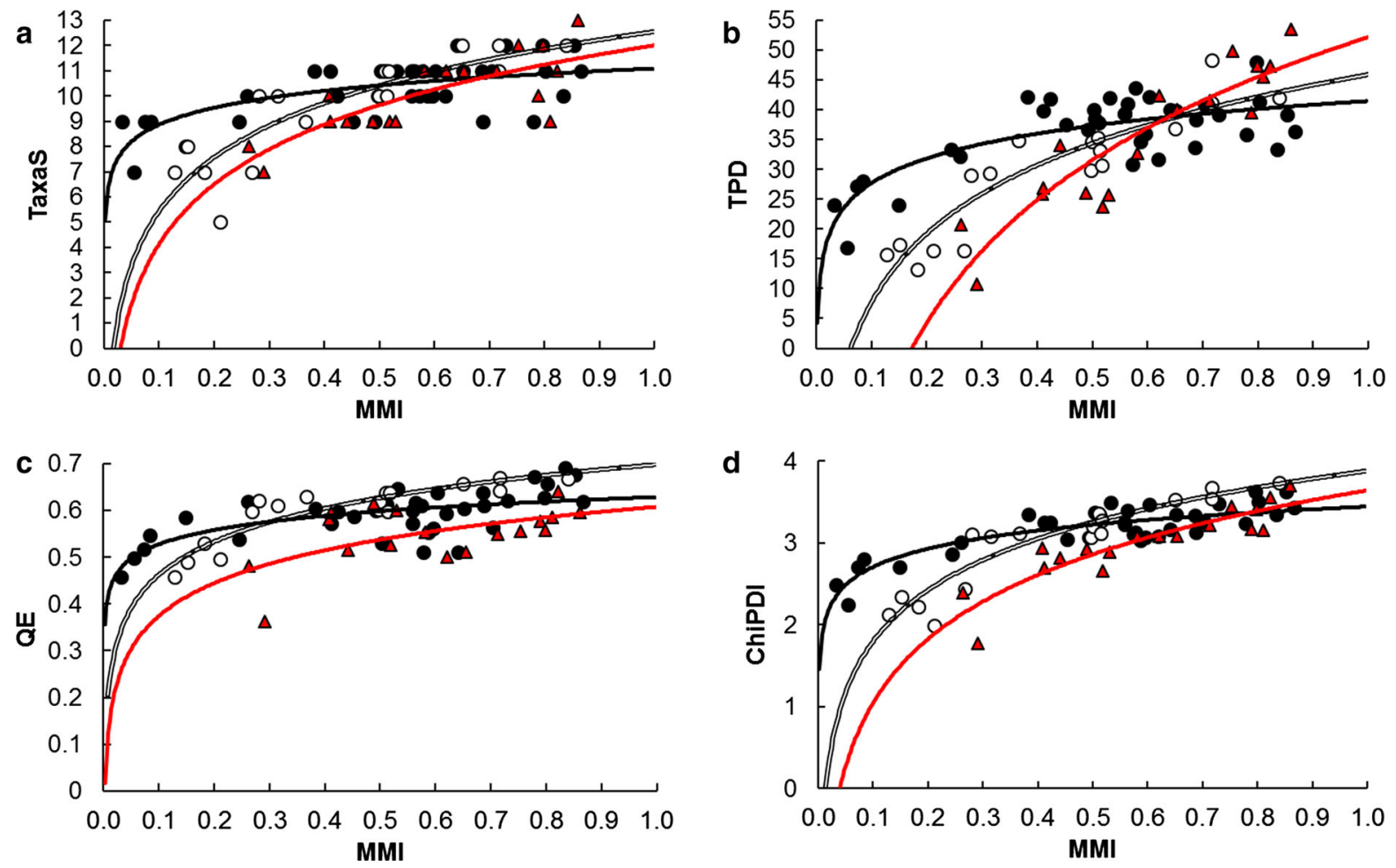

Fig. 4 The results of Sample Rarefaction presented as species accumulation curves for groups of samples from the sites belonging to

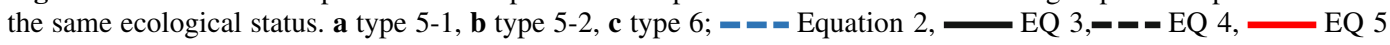

(QE) and total phylogenetic distance (TPD) was prepared. It is calculated as a geometric weighted mean of these metrics with weights resulted from respective coefficients of variance. It is calculated as:

$$
\text { ChiPDI }=\left(\mathrm{TPD} \cdot \mathrm{QE}^{1.93} \cdot \operatorname{TaxaS}^{1.53}\right)^{1 /(1+1.93+1.53)}
$$

Values of ChiPDI and environmental quality are related logarithmically (Fig. 6). The index correlated visibly stronger with the values of environmental quality and its regression coefficients $R^{2}, F, P$ and $\mathrm{RCV}$ indicate better fit accuracy than all core diversity indices (Table 2).

\section{Discussion}

The utility of traditional diversity indices in prediction of environmental quality was found poor in this study, which should not be surprising considering the binomial response of Chironomidae taxonomic data. This type of relationships excludes both traditional indices of species diversity and both indices of taxonomic distinctness from useful predictors of environmental quality. A similar pattern of distribution was also found in the relationships between disturbance or the level of degradation and taxonomic diversity of, e.g., benthic fauna in streams (Townsend et al., 1997), riverine insect larvae (Fore et al., 1996) and riverine Hirudinea (Koperski, 2017). Taxonomic diversity of all these groups is clearly lower at high than at moderate values of environmental quality. Direct values of the species richness values observed during the analysis of samples of 100 individuals were used for comparisons between groups of samples. Such a number of specimens in a sample appear to be low in the case of such a species rich group as Chironomidae. The analysis of the differences in rate of species accumulation along with the increase in both the number of identified individuals and the number of samples shows, however, that the increase in the time and effort devoted to the analysis of more numerous samples would not be compensated by a significant increase in the estimated species richness. The analysis of the rate of species accumulation obtained as a result of the rarefaction procedure 

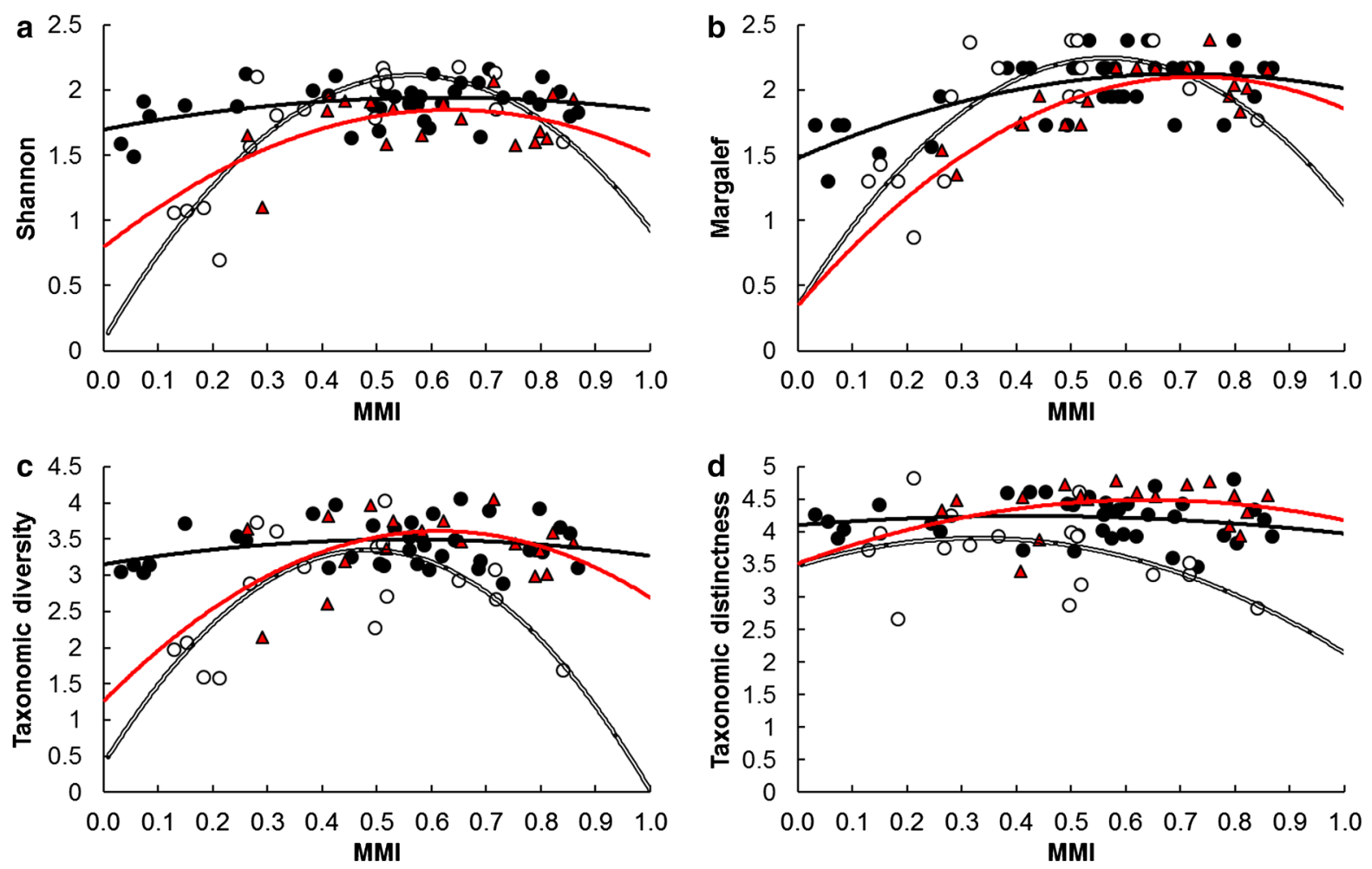

Fig. 5 The relationships between four indices of chironomid diversity and environmental quality expressed by the values of MMI. a Shannon index, b Margalef index, c taxonomic

unambiguously shows the same pattern of dependence of the estimated species richness on the value of ecological status as in the case of observed species richness. This type of response, highest diversity in moderate ecological status, may occur in different taxonomic groups, despite the observed monotonic increase in the general richness of macrobenthos families along with the increase in environmental quality (Koperski \& Meronka, 2017). Only those indices whose extreme values occur at extremely low or high levels of degradation may be practically applied in biological assessment (Hering et al., 2006).

MMI is the only official index used in Poland to assess the ecological status of freshwater environments on the basis of macrobenthos. This index used as a measure of environmental quality, however, seems to be a weaker predictor of macrobenthos biodiversity than, for example, the well-known and widely used index BMWP (Koperski \& Meronka, 2017). Potential reasons for its relative weakness may be, among others: the use of the Shannon index as one of the core index, which is calculated on the basis of

diversity, $\mathbf{d}$ taxonomic distinctness. Responsible lines describe best fitted binomial functions; black circles-sites of type 5-1, white circles-sites of type 5-2, triangles-sites of type 6

data in which Chironomidae, most frequent, most abundant and most divergent ecologically group of macrobenthos are not determined more precisely and the assumption of linear relationship between values of core indices and ecological status.

In spite of its imperfection, the MMI index is, at presence the best way to assess the degradation of different types of watercourses in Poland. Therefore, it was considered that the strong, monotonic correlation of any of the compared indices with MMI values will mean its good ability to predict environmental quality status.

The lack of unambiguous and fixed patterns in species composition (e.g., presence, absence or strong dominance of species) at sites differing in environmental quality is also not surprising, and this is in line with the results of Orendt's research (2018). It seems that the species composition of Chironomidae, as well as other lotic invertebrates, is directly determined by the habitat diversity of bottom substrate, coastal and riparian vegetation at least as strongly as by different types of ecological disturbance including those 
Table 2 Results of analyses of nonlinear regression between environmental quality, expressed by the values of index MMI and different measures of diversity of larval Chironomidae, analyzed independently within the three groups of sampling sites

\begin{tabular}{|c|c|c|c|c|c|c|}
\hline Measures & Sites & Equation & $R^{2}$ & $F$ & $P$ & $\mathrm{RCV}(\%)$ \\
\hline \multirow[t]{3}{*}{ Shannon index (B) } & $5-1$ & $y=-0.64 x^{2}+0.79 x+1.69$ & 0.163 & 3.207 & ns & 7.57 \\
\hline & $5-2$ & $y=-6.37 x^{2}+7.17 x+0.08$ & 0.759 & 18.388 & $1.21 \mathrm{E}-04$ & 14.13 \\
\hline & 6 & $y=-2.21 x^{2}+2.93 x+0.88$ & 0.184 & 1.808 & ns & 11.45 \\
\hline \multirow[t]{3}{*}{ Margalef index (B) } & $5-1$ & $y=-1.29 x^{2}+1.83 x+1.48$ & 0.444 & 13.569 & $4.65 \mathrm{E}-05$ & 9.56 \\
\hline & $5-2$ & $y=-5.97 x^{2}+6.75 x+0.37$ & 0.658 & 13.496 & $5.42 \mathrm{E}-04$ & 14.22 \\
\hline & 6 & $y=-3.51 x^{2}+5.02 x+0.30$ & 0.682 & 17.148 & $1.05 \mathrm{E}-04$ & 7.19 \\
\hline \multirow[t]{3}{*}{ Taxonomic diversity (B) } & $5-1$ & $y=-1.12 x^{2}+1.24 x+3.15$ & 0.077 & 1.410 & ns & 8.61 \\
\hline & $5-2$ & $y=-12.65 x^{2}+12.17 x+0.39$ & 0.528 & 5.733 & 0.0109 & 19.19 \\
\hline & 6 & $y=-5.17 x^{2}+6.63 x+1.48$ & 0.173 & 1.677 & ns & 12.30 \\
\hline \multirow[t]{3}{*}{ Taxonomic distinctness (B) } & $5-1$ & $y=-0.80 x^{2}+0.67 x+4.10$ & 0.022 & 0.389 & $\mathrm{~ns}$ & 7.48 \\
\hline & $5-2$ & $y=-3.87 x^{2}+2.49 x+3.53$ & 0.213 & 0.989 & ns & 13.89 \\
\hline & 6 & $y=-2.08 x^{2}+2.75 x+3.58$ & 0.064 & 0.545 & $\mathrm{~ns}$ & 7.63 \\
\hline \multirow[t]{3}{*}{ Taxonomic richness (L) } & $5-1$ & $y=0.97 \ln (x)+11.09$ & 0.441 & 5.256 & $7.38 \mathrm{E}-06$ & 8.50 \\
\hline & $5-2$ & $y=3.08 \ln (x)+12.56$ & 0.745 & 6.158 & $1.83 \mathrm{E}-05$ & 18.26 \\
\hline & 6 & $y=3.42 \ln (x)+12.01$ & 0.576 & 4.809 & $1.64 \mathrm{E}-04$ & 11.82 \\
\hline \multirow[t]{3}{*}{ Total phylogenetic distance (L) } & $5-1$ & $y=5.98 \ln (x)+41.46$ & 0.589 & 7.086 & $2.96 \mathrm{E}-08$ & 11.10 \\
\hline & $5-2$ & $y=16.67 \ln (x)+46.18$ & 0.839 & 8.630 & $5.49 \mathrm{E}-08$ & 15.63 \\
\hline & 6 & $(y=29.79 \ln (x)+52.18$ & 0.820 & 8.791 & $9.88 \mathrm{E}-08$ & 14.16 \\
\hline \multirow[t]{3}{*}{ Quadratic enthropy (L) } & $5-1$ & $y=0.04 \ln (x)+0.63$ & 0.445 & 5.300 & $6.47 \mathrm{E}-06$ & 6.67 \\
\hline & $5-2$ & $y=0.10 \ln (x)+0.70$ & 0.825 & 7.964 & $1.51 \mathrm{E}-07$ & 6.60 \\
\hline & 6 & $y=0.10 \ln (x)+0.61$ & 0.346 & 3.001 & 0.008 & 9.13 \\
\hline \multirow[t]{3}{*}{ ChiPDI (L) } & $5-1$ & $y=0.32 \ln (x)+3.44$ & 0.738 & 9.937 & $1.00 \mathrm{E}-11$ & 5.40 \\
\hline & $5-2$ & $y=0.90 \ln (x)+3.88$ & 0.870 & 9.811 & $1.68 \mathrm{E}-10$ & 6.89 \\
\hline & 6 & $y=1.13 \ln (x)+3.64$ & 0.830 & 8.925 & $2.39 \mathrm{E}-09$ & 7.69 \\
\hline
\end{tabular}

Equations for the best-fitted functions, coefficient of determination $\left(R^{2}\right)$, values of $F$ function and $P$ values for the fit-accuracy testing procedure and residual coefficients of variance $(\mathrm{RCV} \%)$ are presented

$B$ binomial relationship, $L$ logarithmic relationship, $n s$ nonsignificant $(P>0.05)$

characterized by environmental quality (e.g., Heino et al., 2003; Koperski, 2010). In the article presenting the assumptions and methodology of applying the MMI index (Bis \& Mikulec, 2013), the authors refer to Buffagni et al. (2005) characterizing the possibilities of assessing various types of environmental disturbances by individual core metrics included in the MMI. The abundance of Chironomidae (but not their diversity) partially affects the values of five of the six core metrics included in MMI.

The choice of genetic methods instead of methods based on the taxonomy of freshwater fauna is still under discussion, however, in the case of organisms whose morphological identification is dubious and uncertain (e.g., cryptic species) genetic approaches may be the best and/or only alternative (Wang et al., 2012; Sari et al., 2012, 2015). Among the growing number of studies indicating the superiority of DNA barcoding methods (e.g., Hebert et al., 2003; Jinbo et al., 2011), the great potential of "next-generation sequencing" (NGS) is particularly emphasized (Shokralla et al., 2014) also in the case of Chironomidae (Carew et al., 2013; Brodin et al., 2013).

Well-known and commonly used indices of phylogenetic diversity were applied to develop index ChiPDi: quadratic entropy (Pavoine et al., 2005; Koperski, 2017) and total phylogenetic distance (e.g., Allen et al., 2009; Koperski \& Meronka, 2017). Different types of taxonomic richness of benthic animals (species richness, family richness) 

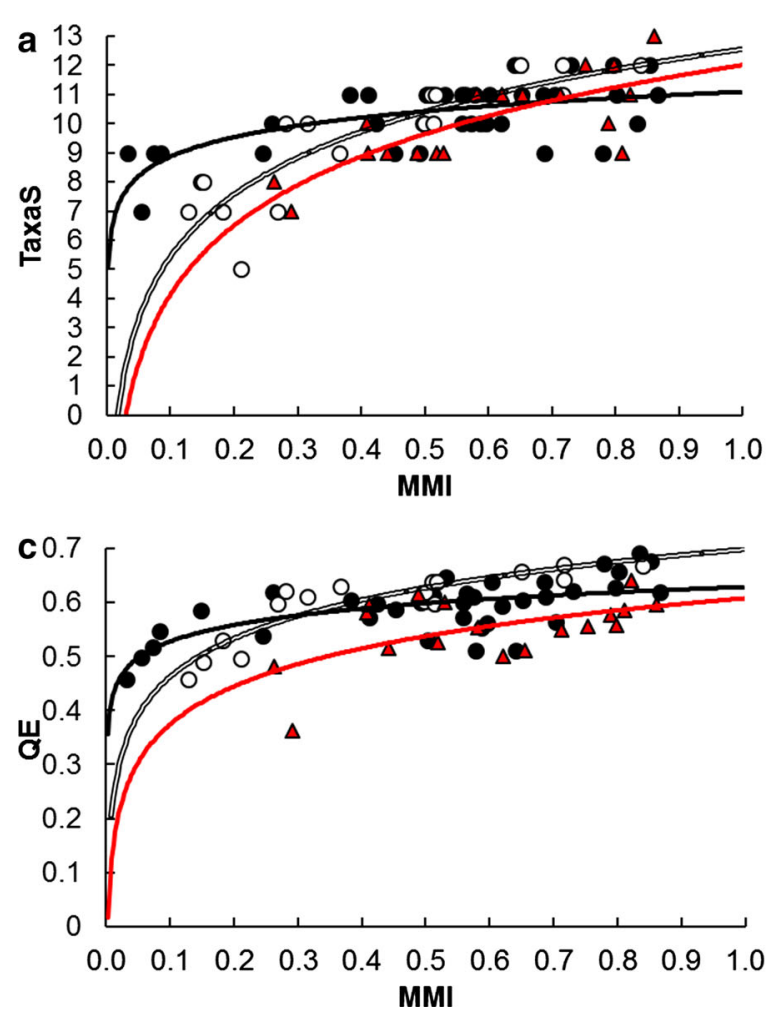

Fig. 6 The relationships between four indices of chironomid diversity and environmental quality expressed by the values of MMI. a taxonomic richness, b total phylogenetic distance (TPD), c quadratic entropy (QE), d ChiPDI (see text).

have been found as a metrics strongly correlated with the disturbance in streams (e.g., Compin \& Cereghino, 2003; Englund et al., 2007). Another commonly used index, Mean Phylogenetic Distance (Webb, 2000; Koperski, 2017) was rejected after preliminary analyzes because it did not show any correlation with MMI values. Presented index ChiPDI seems to be an efficient measure of environmental quality expressed by index MMI, more effective that other tested measures of diversity. It must be, however, emphasized that presented method of environmental quality assessment using the phylogenetic diversity of larval Chironomidae on the basis of prior morphological identification has no practical value yet. The application of such a method could only be possible in combination with an efficient DNA sequencing method using for routine sampling. The method presented by Carew et al. (2013) and Brodin et al. (2013) as the rapid identification of chironomid species using COI barcoding could be a feasible alternative to traditional methods of morphological
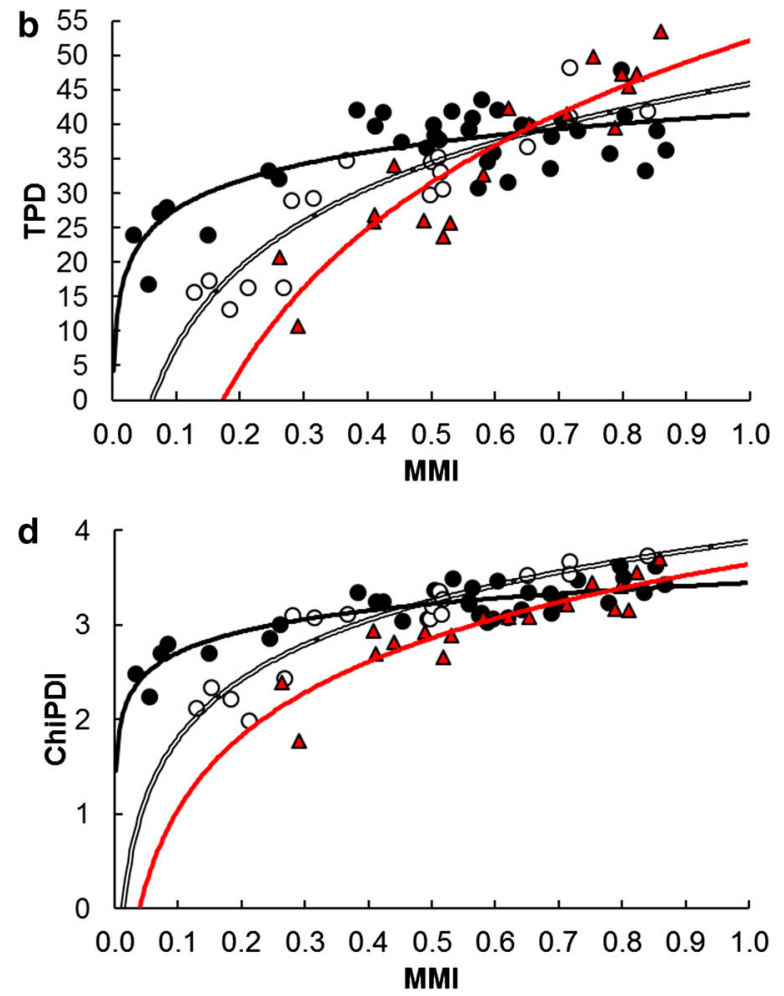

Responsible lines describe best fitted logarithmic functions; black circles-sites of type 5-1, white circles - sites of type 5-2, triangles-sites of type 6

identification for the purposes of bio-monitoring (Pfenninger et al., 2007).

Rapid and standardized method of taxonomic identification based on DNA markers requires advanced technology, sufficiently advanced level of technical proficiency and genetic experitize. Moreover, it needs extended databases covering all species occurred in studied environments and enabling their efficient identification with specific markers (Ekrem et al., 2007). On the other hand, traditional method of morphological identification is highly labor intensive, extremely time-consuming and needs high level of taxonomic expertise. Finally it yet generates data with a variable degree of uncertainty, mainly because of the presence of morphologically cryptic groups of species.

To successfully apply a method based on the phylogenetic diversity of Chironomidae larvae in the bio-assessment of streams, I strongly recommend four consecutive steps.

Standardized, quantitative sampling of numerically appropriate and taxonomically complete set of larvae, 
collected from all types of substrate, occurring at a sampling site. Application of sampling using appropriate artificial substrates dedicated to larval Chironomidae seems to be the best choice. Rapid and errorproof identification of species in a sample on the basis of complete database of genetic markers (COI barcoding seems to be the best choice for now). Calculation of the values of index (indices) based on phylogenetic distances between species and individuals within a sample (e.g., ChiPDI). Determination of the values of environmental quality on the basis of standardized equations describing changes in phylogenetic diversity, on the basis of regression equations (curves).

Acknowledgements The author is grateful to General Inspectorate for Environmental Protection and National Foundation of Environmental Protection for the possibility to obtain and use the data. The study was partially supported by Grant 2011/01/B/NZ9/02590 of National Science Center, Republic of Poland. Author thanks anonymous reviewers for the time and effort devoted to improving the article.

Open Access This article is distributed under the terms of the Creative Commons Attribution 4.0 International License (http:// creativecommons.org/licenses/by/4.0/), which permits unrestricted use, distribution, and reproduction in any medium, provided you give appropriate credit to the original author(s) and the source, provide a link to the Creative Commons license, and indicate if changes were made.

\section{References}

Allen, B., M. Kon \& Y. Bar-Yam, 2009. A new phylogenetic diversity measure generalizing the Shannon index and its application to phyllostomid bats. The American Naturalist 174: 236-243.

Bailey, R. C., R. H. Norris \& T. B. Reynoldson, 2001. Taxonomic resolution of benthic macroinvertebrate communities in bioassessments. Journal of the North American Benthological Society 20: 280-286.

Bailey, R. C., R. H. Norris \& T. B. Reynoldson, 2004. Bioassessment of freshwater ecosystems. Springer, US.

Barbour, M. T., J. Gerritsen, B. D. Snyder \& J. B. Stribling, 1999. Rapid Bioassessment Protocols for Use in Streams and Wadeable Rivers: Periphyton, Benthic Macroinvertebrates and Fish, 2nd ed. U.S. Environmental Protection Agency; Office of Water, Washington, D.C.

Bini, L. M., V. I. Landeiro, A. A. Padial, T. Siqueira \& J. Heino, 2014. Nutrient enrichment is related to two facets of beta diversity for stream invertebrates across the United States. Ecology 95: 1569-1578.

Bis B. \& A. Mikulec, 2013. Przewodnik do oceny stanu ekologicznego rzek na podstawie makrobezkręgowców bentosowych. Biblioteka Monitoringu Środowiska. Inspekcja Ochrony Środowiska, Warszawa. (in Polish).

Brodin, Y., G. Ejdung, J. Strandberg \& T. Lyrholm, 2013. Improving environmental and biodiversity monitoring in the Baltic Sea using DNA barcoding of Chironomidae (Diptera). Molecular Ecology Resources 13: 996-1004.

Buffagni A., S. Erba, S. Birk, M. Cazzola, C. Feld, T. Ofenböck, J. Murray-Bligh, M. T. Furse, R. Clarke, D. Hering, H. Soszka \& W. van de Bund, 2005. Towards European intercalibration for the Water Framework Directive: Procedures and examples for different river types from the E.C. project STAR. 11th STAR deliverable. STAR Contract No: EVK1-CT 2001-00089. Quaderni dell'Istituto di Ricerca sulle Acque 123, Rome, IRSA, 460 p.

Carew, M. E., V. Pettigrove \& A. A. Hoffmann, 2003. Identifying chironomids (Diptera: Chironomidae) for biological monitoring with PCR-RFLP. Bulletin of Entomological Research 93: 483-490.

Carew, M. E., A. D. Miller \& A. A. Hoffmann, 2011. Phylogenetic signals and ecotoxicological responses: potential implications for aquatic biomonitoring. Ecotoxicology 20: 595-606.

Carew, M. E., V. Pettigrove, L. Metzeling \& A. A. Hoffmann, 2013. Environmental monitoring using next generation sequencing: rapid identification of macroinvertebrate bioindicator species. Frontiers in Zoology 10: 45.

Clarke, K. R. \& R. M. Warwick, 1998. A taxonomic distinctness index and its statistical properties. Journal of Applied Ecology 35: 523-531.

Colwell, R. K., A. Chao, N. J. Gotelli, S.-L. Lin, C. X. Mao, R. L. Chazdon \& J. T. Longino, 2012. Models and estimators linking individual-based and sample-based rarefaction, extrapolation and comparison of assemblages. Journal of Plant Ecology 5: 3-21.

Compin, A. \& R. Céréghino, 2003. Sensitivity of aquatic insect species richness to disturbance in the Adour-Garonne stream system (France). Ecological indicators 3: 135-142.

Cranston, P. S., 1982. A key to the larvae of the British Orthocladiinae (Chironomidae). Scientific Publications of the Freshwater Biological Association 45: 1-152.

Cranston, P. S., D. R. Oliver \& O. A. Sæther, 1983. Chironomidae of the Holarctic region - Keys and diagnoses. Part 1. Entomologica Scandinavica Supplement 19: 149-291.

Cranston, P. S., 2010. Chiro Key. [available on internet at http:// chirokey.skullisland.info]

Cranston, P. S., N. B. Hardy \& G. E. Morse, 2012. A dated molecular phylogeny for the Chironomidae (Diptera). Systematic Entomology 37: 172-188.

Cranston, P. S., 1995. Systematics. In Armitage, P. D., P. S. Cranston \& L. C. V. Pinder (eds), The Chironomidae: biology and ecology of non-biting midges. Chapman and Hall, London.

De Bisthoven, L. J. \& A. Gerhardt, 2003. Chironomidae (Diptera, Nematocera) fauna in three small streams of Skania, Sweden. Environmental Monitoring and Assessment 83: 89-102.

Demin, A. G., N. V. Polukonova \& N. S. Mugue, 2011. Molecular phylogeny and the time of divergence of minges (Chironomidae, Nematocera, Diptera) inferred from a partial nucleotide sequence of the cytochrome oxidase I gene (COI). Russian Journal of Genetics 47: 1168-1180. 
De Pauw, N. \& G. Vanhooren, 1983. Method for biological quality assessment of watercourses in Belgium. Hydrobiologia 100: 153-168.

Directive 2000/60/EC (2000) of the European Parliament and of the Council establishing a framework for Community action in the field of water policy. OJ L327, 22.12.2000

Ekrem, T. \& E. Willassen, 2004. Exploring Tanytarsini relationships (Diptera: Chironomidae) using mitochondrial COII gene sequences. Insect Systematics \& Evolution 35: 263-276.

Ekrem, T., E. Willassen \& E. Stur, 2007. A comprehensive DNA sequence library is essential for identification with DNA barcodes. Molecular Phylogenetics and Evolution 43: 530-542.

Englund, R. A., M. G. Wright \& D. A. Polhemus, 2007. Aquatic insect taxa as indicators of aquatic species richness, habitat disturbance, and invasive species impacts in Hawaiian streams. Bishop Museum Bulletin in Cultural and Environmental Studies 3: 207-232.

Faith, D. P. \& A. M. Baker, 2006. Phylogenetic diversity and biodiversity conservation: some bioinformatics challenges. Evolutionary Bioinformatics 2: 121-128.

Faith, D. P., C. A. Lozupone, D. Nipperess \& R. Knight, 2009. The cladistic basis for the phylogenetic diversity (PD) measure links evolutionary features to environmental gradients and supports broad applications of microbial ecology's "phylogenetic beta diversity" framework. International Journal of Molecular Sciences 10: 4723-4741.

Ferrington, L. C., 2008. Global diversity of non-biting midges (Chironomidae; Insecta-Diptera) in freshwater. Hydrobiologia 595(1): 447.

Fittkau, E. J. \& S. S. Roback, 1983. Chironomidae of the Holarctic region - Keys and diagnoses. Part 1. Entomologica Scandinavica Supplement 19: 33-112.

Fore, L. S., J. R. Karr \& R. W. Wisseman, 1996. Assessing invertebrate responses to human activities: evaluating alternative approaches. Journal of the North American Benthological Society 15: 212-231.

Franquet, E., 1999. Chironomid assemblage of a Lower-Rhône dike field: relationships between substratum and biodiversity. Hydrobiologia 397: 121-131.

Furse, M., D. Hering, O. Moog, P. Verdonschot, R. K. Johnson, K. Brabec, K. Gritzalis, A. Buffagni, P. Pinto, N. Friberg, J. Murray-Bligh, J. Kokes, R. Alber, P. Usseglio-Polatera, P. Haase, R. Sweeting, B. Bis, K. Szoszkiewicz, H. Soszka, G. Springe, F. Sporka \& I. Krno, 2006. The STAR project: context objectives and approaches. Hydrobiologia 566: $3-29$.

Galas, J., E. Dumnicka \& A. Galus-Barchan, 2014. A comparison of various indices based on benthic macrofauna for the assessment of the ecological status of selected Carpathian streams. Oceanological and Hydrobiological Studies 43: 123-130.

Guryev, V., I. Makarevitch, A. Blinov \& J. Martin, 2001. Phylogeny of the genus Chironomus (Diptera) inferred from DNA sequences of mitochondrial cytochrome $b$ and cytochrome oxidase I. Molecular Phylogenetics and Evolution 19: 9-21.

Grzybkowska, M., A. Temech \& M. Dukowska, 1996. Impact of long-term alternations of discharge and spate on the chironomid community in the lowland Widawka River (Central Poland). Hydrobiologia 324: 107-115.

Grzybkowska, M., M. Dukowska, A. M. Takeda, J. Majecki \& L. Kucharski, 2003. Seasonal dynamics of macroinvertebrates associated with submersed macrophytes in a lowland river downstream of a dam reservoir. International Journal of Ecohydrology and Hydrobiology 3: 399-408.

Hammer, Ø., D. A. T. Harper \& P. D. Ryan, 2001. PAST: Paleontological statistics software package for education and data analysis. Palaeontologia Electronica 4: 9.

Hebert, P. D., S. Ratnasingham \& J. R. de Waard, 2003. Barcoding animal life: cytochrome c oxidase subunit 1 divergences among closely related species. Proceedings of the Royal Society of London B: Biological Sciences 270(Suppl 1): 96-99.

Heino, J., T. Muotka \& R. Paavola, 2003. Determinants of macroinvertebrate diversity in headwater streams: regional and local influences. Journal of Animal Ecology 72: 425-434.

Hering, D., C. K. Feld, O. Moog \& T. Ofenböck, 2006. Cook book for the development of a Multimetric Index for biological condition of aquatic ecosystems: experiences from the European AQEM and STAR projects and related initiatives. Hydrobiologia 566: 311-324.

Jinbo, U., T. Kato \& M. Ito, 2011. Current progress in DNA barcoding and future implications for entomology. Entomological Science 14: 107-124.

Klink, A. G. \& H. K. M. Moller-Pillot, 2003. Chironomidae larvae. Key to higher taxa and species of the lowlands of Northwestern Europe. World Biodiversity Database, ETI.

Koperski, P., 2009. Reduced diversity and stability of chironomid assemblages (Chironomidae, Diptera) as the effect of moderate stream degradation. Polish Journal of Ecology 57: $125-138$.

Koperski, P., 2010. Diversity of macrobenthos in lowland streams: ecological determinants and taxonomic specificity. Journal of Limnology 69: 88-101.

Koperski, P., 2017. Taxonomic, phylogenetic and functional diversity of leeches (Hirudinea) and their suitability in biological assessment of environmental quality. Knowledge \& Management of Aquatic Ecosystems 418: 49.

Koperski, P. \& R. Meronka, 2017. Environmental quality of a stream can be better predicted by phylogenetic than by taxonomic diversity. Knowledge \& Management of Aquatic Ecosystems 418: 16.

Kownacki, A., 2000. Diversity of benthic macroinvertebrates as a monitoring method for polluted rivers. Acta Hydrobiologica 42: 187-206.

Krosch, M. N., P. S. Cranston, L. M. Bryant, F. Strutt \& S. R. McCluen, 2017. Towards a dated molecular phylogeny of the Tanypodinae (Chironomidae, Diptera). Invertebrate Systematics 31: 302-316.

Larocque-Tobler, I., 2014. The Polish sub-fossil chironomids. Palaeontologia Electronica 17: 1-28.

Lepš, J., F. de Bello, S. Lavorel \& S. Berman, 2006. Quantifying and interpreting functional diversity of natural communities: practical considerations matter. Preslia 78: 481-501.

Lindegaard, C., 1995. Classification of water-bodies and pollution. In Armitage, P. D., P. S. Cranston \& L. C. V. Pinder (eds), The Chironomidae: biology and ecology of nonbiting midges. Chapman and Hall, London. 
Lydy, M. J., C. G. Crawford \& J. W. Frey, 2000. A comparison of selected diversity, similarity, and biotic indices for detecting changes in benthic-invertebrate community structure and stream quality. Archives of Environmental Contamination and Toxicology 39: 469-479.

Magurran, A. E., 2013. Measuring biological diversity. WileysBlackwell, Oxford.

Milošević, D., D. Mančev, D. Čerba, M. S. Piperac, N. Popović, A. Atanacković, J. Đuknić, V. Simić \& M. Paunović, 2018. The potential of chironomid larvae-based metrics in the bioassessment of non-wadeable rivers. Science of The Total Environment 616: 472-479.

Montagna, M., V. Mereghetti, V. Lencioni \& B. Rossaro, 2016. Integrated taxonomy and DNA barcoding of Alpine midges (Diptera: Chironomidae). PloS One 11: e0149673.

Moore, A. A. \& M. A. Palmer, 2005. Invertebrate biodiversity in agricultural and urban headwater streams: implications for conservation and management. Ecological Applications 15: 1169-1177.

Oliver, D. R., 1983. Chironomidae of the Holarctic region Keys and diagnoses. Part 1. Entomologica Scandinavica Supplement 19: 115-140.

Orendt, C., 2018. Results of 10 years sampling of Chironomidae from German lowland running waters differing in degradation. Journal of Limnology. https://doi.org/10.4081/ jlimnol.2018.1790.

Pavoine, S., S. Ollier \& D. Pontier, 2005. Measuring diversity from dissimilarities with Rao's quadratic entropy: Are any dissimilarities suitable? Theoretical Population Biology 67: 231-239.

Pfenninger, M., C. Nowak, C. Kley, D. Steinke \& B. Streit, 2007. Utility of DNA taxonomy and barcoding for the inference of larval community structure in morphologically cryptic Chironomus (Diptera) species. Molecular Ecology 16: 1957-1968.

Pinder, L. C. V., 1995. The habitats of chironomid larvae. In Armitage, P. D., P. S. Cranston \& L. C. V. Pinder (eds), The Chironomidae: biology and ecology of non-biting midges. Chapman and Hall, London.

Pinder, L. V. \& F. Reiss, 1983. Chironomidae of the Holarctic region - Keys and diagnoses. Part 1. Entomologica Scandinavica Supplement 19: 293-435.

Rabeni, C. F. \& N. Wang, 2001. Bioassessment of streams using macroinvertebrates: are the Chironomidae necessary? Environmental Monitoring and Assessment 71: 177-185.

Rae, J. G., 1989. Chironomid midges as indicators of organic pollution in the Scioto River Basin, Ohio. Ohio Journal of Science 89: 5-9.

Rae, J. G., 2004. The colonization response of lotic chironomid larvae to substrate size and heterogeneity. Hydrobiologia 524: $115-124$.

Sæther, O. A., 1977. Taxonomic studies on Chironomidae: Nanocladius, Pseudochironomus, and the Harnischia complex. Bulletin of the Fisheries Research Board of Canada 196: 1-287.

Saether, O. A., 1983. Chironomidae of the Holarctic region Keys and diagnoses. Part 1. Entomologica Scandinavica Supplement 19: 141-148.

Sari, A., M. Duran \& F. Bardakci, 2012. Discrimination of Orthocladiinae species (Diptera: Chironomidae) by using cytochrome c oxidase subunit I. Acta Zoologica Bulgarica 4: 73-80.

Sari, A., M. Duran, A. Sen \& F. Bardakci, 2015. Investigation of Chironomidae (Diptera) relationships using mitochondrial COI gene. Biochemical Systematics and Ecology 59: 229-238.

Siciński J. 2007. Ochotkowate (Chironomidae). In: W. Bohdanowicz, E. Chudzicka, I. Filipiuk \& E. Skibińska (eds) Fauna Polski - charakterystyka i wykaz gatunków vol. II, Muzeum i Instytut Zoologii PAN, Warszawa (in Polish).

Schweiger, O., S. Klotz, W. Durka \& I. Kühn, 2008. A comparative test of phylogenetic diversity indices. Oecologia 157: 485-495.

Shokralla, S., J. F. Gibson, H. Nikbakht, D. H. Janzen, W. Hallwachs \& M. Hajibabaei, 2014. Next-generation DNA barcoding: using next-generation sequencing to enhance and accelerate DNA barcode capture from single specimens. Molecular Ecology Resources 14: 892-901.

Sinclair, C. S. \& S. E. Gresens, 2008. Discrimination of Cricotopus species (Diptera: Chironomidae) by DNA barcoding. Bulletin of Entomological Research 98: 555-563.

Serra, S. R., M. A. Graça, S. Dolédec \& M. J. Feio, 2017. Chironomidae traits and life history strategies as indicators of anthropogenic disturbance. Environmental Monitoring and Assessment 189: 326.

Spies, M. \& O. A. Sæther, 2004. Notes and recommendations on taxonomy and nomenclature of Chironomidae (Diptera). Zootaxa 752: 1-90.

Syrovátka, V., J. Schenková \& K. Brabec, 2009. The distribution of chironomid larvae and oligochaetes within a stonybottomed river stretch: the role of substrate and hydraulic characteristics. Fundamental and Applied Limnology 174: 43-62.

Townsend, C. R., M. R. Scarsbrook \& S. Doledec, 1997. The intermediate disturbance hypothesis refugia and biodiversity in streams. Limnology and Oceanography 42: 938-949.

Vallenduuk, H. J. \& E. Morozova, 2005. Cryptochironomus. An identification key to the larvae and pupal exuviae in Europe. Lauterbornia 55: 1-22.

Wang, G., C. Li, X. Guo, D. Xing, Y. Dong, Z. Wang, Y. Zhang, M. Liu, Z. Zheng, H. Zhang, Z. Wu \& X. Zhu, 2012. Identifying the main mosquito species in China based on DNA barcoding. PLoS ONE 7: e47051.

Warwick, R. M. \& K. R. Clarke, 1995. New biodiversity measures reveal a decrease in taxonomic distinctness with increasing stress. Marine Ecology Progress Series 129: 301-305.

Webb, C. O., 2000. Exploring the phylogenetic structure of ecological communities: an example for rain forest trees. The American Naturalist 156: 145-155.

Winter, M., V. Devictor \& O. Schweiger, 2013. Phylogenetic diversity and nature conservation: where are we? Trends in Ecology and Evolution 28: 199-204.

Yoccoz, N. G., J. D. Nichols \& T. Boulinier, 2001. Monitoring of biological diversity in space and time. Trends in Ecology \& Evolution 16: 446-453.

Publisher's Note Springer Nature remains neutral with regard to jurisdictional claims in published maps and institutional affiliations. 